\title{
Leader-Member Exchange and Affective Commitment to Change: Mediating Role of Change Self-Efficacy
}

\author{
Dwi Andriani Puspitasari ${ }^{1, *}$, Wustari L. Mangundjaya ${ }^{1}$ \\ ${ }^{I}$ Department of Psychology Universitas Indonesia Depok, Indonesia \\ *Corresponding author.Email:dwiapuspitasari@gmail.com,wustari@gmail.com
}

\begin{abstract}
Rapid changes in the business environment require organizations to have the ability to adjust to the changes and maintain their competitive advantage. Success in dealing with change must be supported by organizational members' commitment to change. Organizational members' commitment to change is effected by the leader with the relationship quality between superior and subordinate (leader-member exchange/LMX) and by the person with their change self-efficacy. This study investigates the effect of LMX and its dimensions (professional respect, affect, contribution, and loyalty) on affective commitment to change, which is still limited. As well as to examine the role of change self-efficacy as a mediator in the relationship between LMX and affective commitment to change. Data were collected from 612 respondents who worked at a social security institution in Indonesia. Statistical analysis using Structural Equation Modelling on LISREL 8.80 shows that the dimensions of LMX (effect and contribution) have a positive influence on affective commitment to change, and change self-efficacy has a significant role in mediating effect affect and contribution to affective commitment to change. The results of this study are expected to provide information on the dimensions of LMX that effect on employees' affective commitment to change by mediating change self-efficacy.
\end{abstract}

Keywords: change self-efficacy, leader-member exchange, commitment to change

\section{INTRODUCTION}

The rapidly developing business environment forces the organization to be able to be dynamic which means that being able to adjust to the changes that occur. There is a need to develop the organization, in order to follow the pressure to integrate and collaborate, as well as to adapt to new trends or fashions, new leadership in organizations, to adjust political pressure and power, and to face high competition [1]. Resources in organizations, economic change, awareness of the importance social responsibility, climate change, development of information technology and social networking [2] are both internal and external factors are the challenges, that drive organizations to change that need to be faced and overcome.

Changes in the organization must be supported by the people in the organization, as the source of success or failure of a change program is the people. Lack of support or commitment from members of the organization for organizational change is one of the causes of failure of organizational change [3]. Commitment to change encourages someone to take actions that are considered important for the successful execution of the initiative of change [4]. Commitment to change is influenced by the relationship between superior and subordinate [3]. The superior and subordinate relationship has a significant role in creating a healthy work environment that leads to the level of organizational success in achieving their goals
[5]. The phenomenon of superior and subordinate relationship is often described in a dyadic relationship between superior and subordinate (leader-member exchange/LMX). LMX within the scope of organizational leadership is used as an approach to studying the relationship between leadership processes and expected outcomes [6]. LMX has four dimensions, namely professional respect, affect, contribution, and loyalty [7]. Several studies have shown that each of these dimensions can predict different outcomes differently [7]. Research on LMX showed a significant relationship with many important outcomes, including organizational commitment [8], [9] and is considered a positive predictor of organizational commitment [10]. However, there is still a very limited studies in relation to the impact of LMX to commitment to change.

In addition to the superior and subordinate relationship described in LMX, an individual's belief in their ability (efficacy) is a factor that can influence commitment to change [3]. Employee beliefs about his/her ability (competence) to achieve success [11]. Beliefs that they have the competences in dealing with the situations of change or what is called change self-efficacy also can affect affective commitment to change [12]. Therefore, in a change situation, superiors not only communicate differences but also there is a need to support their members' beliefs about changes in the organization [13]. This study was conducted to testing the role of change selfefficacy in the context of the relationship between LMX and its dimensions (professional respect, affect, 
contribution, and loyalty) with affective commitment to change.

\section{LITERATURE REVIEW}

\subsection{Leader-Member Exchange}

Leader-member exchange (LMX) describes the quality of superior and subordinate relationship, where superior builds a dissimilar relationship or exchange with each subordinate rather than using the same leadership style in dealing with subordinate [14]. According to Liden \& Maslyn [7], LMX has four dimensions, namely professional respect, affect, contribution, and loyalty. Professional respect defined as the perception of the level of reputation of excelling at his/her line of work that is built by subordinates of the reciprocal relationships carried out, inside or outside the organization, where perceptions may be based on the person's historical data such as experience relating to others, opinions about the person from other people inside and outside the organization, and professional awards or acknowledgment received [7]. Affect refers to the mutual affection members of the dyad have for each other based primarily on interpersonal attraction rather than work or professional values. Contribution refers to perceptions about the current level of work-oriented activities of each member submitted towards the common goal (explicit or implicit) of the dyad; the extent to which members of the reciprocal relationship handle responsibilities and complete tasks that go beyond the job description and also the extent to which the leader provides resources and opportunities for such activities. Loyalty refers to loyalty to one another, between superiors and subordinates openly supporting each other in terms of actions and character. Superiors prefer asking subordinates who are loyal to do work that requires an independent opinion or responsibility. Loyalty involves a fidelity to the individual that is generally consistent from situation to situation.

\subsection{Affective Commitment to Change}

Commitment to change is a mindset that leads someone to take actions considered necessary for the successful execution of the initiative of change, which consists of three dimensions, namely normative commitment, continuance commitment, and affective commitment [4]. Furthermore, Herscovitch \& Meyer [4] explain normative commitment

to change as a feeling of obligation to support change, where employees will remain in the organization because they feel they must remain in the organization. Continuance commitment to change is the employee's perception of the costs that may arise from the execution of the change. Affective commitment to change (ACTC) refers to positive feelings towards the changes made and the belief that change will benefit. Therefore, affective commitment to change is considered the most important dimension that can predict employees' efforts in supporting the success of organizational change [15]. As a result, affective commitment to change will be the focus of this study.

\subsection{Change Self-Efficacy}

Self-efficacy defined as someone's belief in their ability to take necessary actions in dealing with a particular situation [11], including in dealing with changes. According to Wanberg \& Banas [16], change self-efficacy (CSE) is the ability that individuals feel to handle changes in certain situations and functions well in the workplace although there is a change in the organization. Individuals will not succeed in making changes if they are not sure of their abilities. The individual with high change self-efficacy is unlikely to be pressured by feelings of inadequacy and are expected to persevere in their efforts to manage the organizational change process, will tend to understand great ideas, take positive actions, and undertake initiatives of change. The individual with low levels of change selfefficacy will tend to focus on their feelings of incompetence and show passive behavior, negative work attitudes, and failure to handle change situations because they feel unsure of their abilities to respond to the demands of certain organizational changes.

\subsection{Leader-Member Exchange, Change Self- Efficacy, and Affective Commitment to Change}

LMX emphasizes the dyadic relationships that develop between superior and subordinate can predict outcomes [6]. Dyadic relationships that develop are based on social exchange theory [17], [8], [18], [6]. Social Exchange Theory explains there is a relationship between behavior and environment that influences one another, whether the relationship provides beneficial or detrimental reciprocity. The relationship or social interaction is carried out in the form of exchange. According to this theory, individuals will tend to repeat or continue interaction (exchange) if the interaction is considered positive and provides benefits for themselves. In contrast, the interactions (exchanges) that are deemed detrimental will tend not to be repeated or continued.

The practice of this theory in LMX explains that the relationship between superior and subordinate is a reciprocal relationship, where the interaction between them has exchange consequences, with the main aspect is the quality of exchange [8]. If the exchange behavior is received positively by both parties and they are satisfied with the response, then the exchange will continue [18]. A high LMX relationship is often shown by increased satisfaction and mutual influence, more access to resources, open communication, and the behavior that exceeds expected [6]. A low LMX relationship is indicated by limited resources and information, leading to 
dissatisfaction, and low employee commitment [6]. The exchange between superior and subordinate is based on professional respect (a reputation that is built), affect (liking each other), loyalty (mutual loyalty to each other), and contribution (task-related behavior). The dimensions of LMX can predict different outcomes [7], including affective commitment to change.

The study conducted by Mangundjaya [3] showed that the feeling of a person's ability (efficacy) has a significant positive effect on a commitment to change. Moreover, the previous study showed that between LMX and organizational commitment there was a positive relationship [8], [9], [10]. Although those researches are in the relationship with organizational commitment, the study of Mangundjaya [3] that showed there was a significant positive impact of organizational commitment and affective commitment to change, it can be assumed that there is a positive relationship between LMX and affective commitment to change. Based on these arguments, the following hypotheses are proposed:

Hypothesis 1: Affect has a positive effect on affective commitment to change.

Hypothesis 2: Loyalty has a positive effect on affective commitment to change.

Hypothesis 3: Contribution has a positive effect on affective commitment to change.

Hypothesis 4: Professional respect has a positive effect on affective commitment to change

The relationship between superiors and subordinates is related to employee self-efficacy, where subordinates who feel the relationship quality with the superiors is high feel the support of the leader [3] and more rewards, positive feedback from leaders [19], as well as feeling a sense of belonging, and as a form of exchange members will show through commitment [20]. In the situation of change, superiors need to support their subordinates' beliefs about the change in the organization [13] because subordinates' self-efficacy influences their choices in behavior. Subordinates' beliefs about the changes that occur affect their commitment to change [3].

In the change context, members who feel confident in their abilities will be able to manage the change. Several studies have shown that there is a significant relationship between change self-efficacy and affective commitment to change [21], [22].

Based on these arguments, the following hypotheses are proposed:

Hypothesis 5: Change self-efficacy has a role as a mediator between affect and affective commitment to change.

Hypothesis 6: Change self-efficacy has a role as a mediator between loyalty and affective commitment to change.

Hypothesis 7: Change self-efficacy has a role as a mediator between contribution and affective commitment to change.

Hypothesis 8: Change self-efficacy has a role as a mediator between professional respect and affective commitment to change.

The proposed research model is as follows:

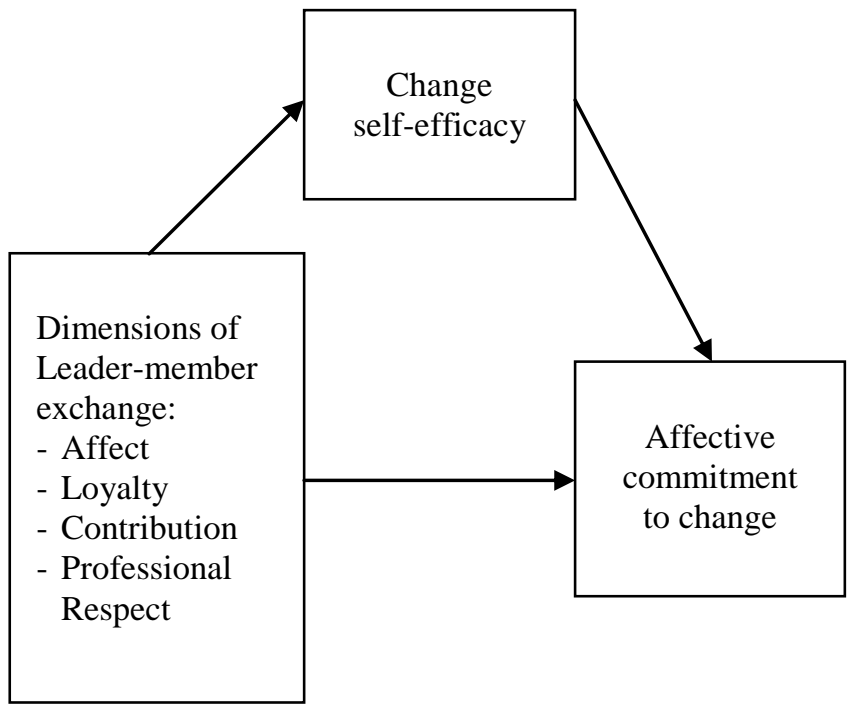

Figure 1 Hypothesized Model

\section{METHOD}

\subsection{Participants and Procedures}

Participants in this study were employees who worked both at the regional and the head office of government institutions with a public legal entity in the field of social security. Institutions that have representative offices spread throughout the provincial capital in Indonesia with the Head Office located in Jakarta. Participant criteria are employees at the staff level who have direct supervisors and has to experience organizational change, permanent staff, had been working at least 2 (two) years, and had experienced of organizational changes.

The questionnaire was distributed and accessed online by 800 participants, and 612 participants who filled out the questionnaire online completely (response rate $=76.5 \%$ ). Participants consisted of $53.3 \%$ men and $46.7 \%$ women, with the average age was 31.76 years $(\mathrm{SD}=6.67)$. The level of education of participants varied, $80.7 \%$ undergraduate, $10.5 \%$ diploma, and $8.8 \%$ postgraduate, with the average tenure was 7.44 years of $(\mathrm{SD}=5.93)$

\subsection{Measurement}

\subsubsection{Leader-Member Exchange (LMX)}

Leader-member exchange (LMX) was measured using 12 items Leader-Member Exchange Multi Dimension Measurement develop by Liden and Maslyn [7], has been 
translated into Indonesian. This Scale uses a Likert scale of 1-6 scale $(1=$ strongly disagree, $6=$ strongly agree $)$. One example statement is "I admire my supervisor's professional skills." Cronbach's Alpha coefficient of this scale is 0.89 .

\subsubsection{Change Self-Efficacy (CSE)}

Change self-efficacy (CSE) was measured using four items Change-Specific Self-Efficacy developed by Ashford [23], has been translated into Indonesian. This Scale uses a Likert scale of 1-6 scale $(1=$ strongly disagree, $6=$ strongly agree). One example statement is "I have reason to believe I may not perform well in my job situation following the change." Cronbach's Alpha coefficient of this scale is 0.77.

\subsubsection{Affective Commitment to Change (ACTC)}

Affective commitment to change (ACTC) was measured by using the six items Commitment to Change Inventory from Herscovitz \& Meyer [4]. This Scale uses a Likert scale of 1-6 scale $(1=$ strongly disagree, $6=$ strongly agree). One example statement is "This change serves an important purpose." This measurement scale has been translated into Bahasa Indonesia. Cronbach's Alpha coefficient of this scale is 0.84 .

\subsection{Data Analysis}

This study uses Structural Equation Modeling (SEM) to analyse the data, including Confirmatory Factor Analysis (CFA) to test the validity and reliability of the measures. The hypotheses were analysed using SEM analysis on LISREL 8.80 .

\section{RESULTS AND DISCUSSION}

\subsection{Results}

Based on the validity and reliability test using CFA, the standardized loading factor for the observed variables between 0.60 to 2.06 are above 0.5 , it means that all variables are valid. The Average Variance Extracted (AVE) for each observed variable is affective 0.86 , loyalty 0.79 , contribution 0.75 , professional respect 0.82 , change-related self-efficacy 0.70 , and affective commitment to change 0.72 , shows that all instruments are reliable (AVE>0.5).

All dimensions of LMX (affect, loyalty, contribution, and professional respect) have a positive relationship with affective commitment to change $(\mathrm{r}=.52, \mathrm{p}<.01 ; \mathrm{r}=.28$, $\mathrm{p}<.01 ; \mathrm{r}=.10, \mathrm{p}<.05 ; \mathrm{r}=.22, \mathrm{p}<.01$, respectively) and change self-efficacy $(r=.17, p<.01 ; r=.72, p<.01 ; r=.49$, $\mathrm{p}<.01 ; \mathrm{r}=.38, \mathrm{p}<.01$, respectively). Change self-efficacy has a positive relationship with affective commitment to change $(r=.22, p<.01)$. The relationship between LMX, change self-efficacy, and affective commitment to change with demographic (gender, age, education, tenure) shows that age has a positive relationship with the dimensions of LMX, affect and loyalty $(\mathrm{r}=.11, \mathrm{p}<.01 ; \mathrm{r}=.08, \mathrm{p}<.05)$; gender has a negative relationship with the dimensions of LMX, loyalty and contribution $(\mathrm{r}=-.10, \mathrm{p}<.05 ; \mathrm{r}=-.11$, $\mathrm{p}<.01)$; tenure has a positive relationship with the dimensions of LMX affect $(r=.0 .9, \mathrm{p}<.05)$ and negative relationship with professional respect $(\mathrm{r}=-.09, \mathrm{p}<.05)$. Education does not have a relationship with all dimensions of LMX, change self-efficacy, and affective commitment to change; gender, age, and tenure have no relationship with change self-efficacy and affective commitment to change.

The results of the structural model analysis obtained a model fit with data $(\chi 2=718.26, \mathrm{df}=190 ; \chi 2 / \mathrm{df}=3.78$, GFI $=0.90$, CFI $=0.97 ;$ PNFI $=0.79$, NFI $=0.96$, RMSEA $=0.067)$. Statistical test results indicate that affect and contribution have a positive influence on affective commitment to change $(\gamma=0.26, \mathrm{t}=3.26 ; \gamma=0.26, \mathrm{t}=$ 4.94 , respectively), while loyalty and professional respect do not have a significant effect on affective commitment to change $(\gamma=-0.05, \mathrm{t}=-1.00 ; \gamma=-0.07, \mathrm{t}=-0.94)$. Hypothesis 1 and hypothesis 3 were supported, which means that the higher the perception of affect or contribution, the higher the support and willingness to change. Meanwhile, hypothesis 2 and hypothesis 4 were not supported. Statistical test results also showed that change self-efficacy has significant role in mediating effect affect and contribution to affective commitment to change (indirect effect $=0.13, \mathrm{t}=3.47$; indirect effect $=0.08, \mathrm{t}=$ 3.38 ), and change self-efficacy has no role in mediating the effect of loyalty and professional respect on affective commitment to change (indirect effect $=-0.04, \mathrm{t}=-1.47$; indirect effect $=-0.06, \mathrm{t}=-1.81)$. Hypothesis 5 and hypothesis 7 were supported, while hypothesis 6 and hypothesis 8 were not supported.

\subsection{Discussion}

This study examines the mediating role of change selfefficacy on the relationship between dimensions of LMX on affective commitment to change. Structural Equation Modelling analysis on LISREL 8.80 is used to test the proposed hypothesis. The dimensions of LMX, affect and contribution, has a significant positive effect with affective commitment to change, where contribution has a more significant effect on affective commitment to change. This shows that commitment is significantly related to contribution than affect [7], where subordinates contribute more to workgroups to benefit the organization, not just superiors. Affect as a dimension of LMX that has a significant positive effect on affective commitment to change shows that the higher the perception of subordinates of the quality of relationships established based on an interpersonal interest that is considered to provide personal benefits, the higher the support and desire indicated subordinates to change. Contribution as a dimension of 
LMX which has a significant positive effect on affective commitment to change shows that the higher subordinates' perceptions about the balance of contributions made by both parties (subordinates hold responsibilities and complete tasks that go beyond description jobs and superiors provide resources and opportunities for subordinates to finish their job), the higher the support and desire shown by subordinates to change. The results of this study also found that change self-efficacy has a significant role in mediating the effect of the dimensions of $\mathrm{L}$ MX affect and contribution to affective commitment to change. This finding showed that self-efficacy to handle changes in certain situations and function well at work despite demands for change [16] is a factor that enables to have a positive effect on a commitment to change [3]. These findings confirmed that the dimensions of LMX are multidimensional, where these dimensions can predict different outcomes [7].

In this study, participant demographics age has a positive relationship with the dimensions of LMX such as affect and loyalty. Gender has a negative relationship with the dimensions of LMX loyalty and contribution. Tenure has a positive relationship with the dimensions of LMX affect and negative relationship with professional respect. Education does not have a relationship with all dimensions of LMX (professional respect, affect, contribution, and loyalty), affective commitment to change, and change selfefficacy. To sum, age, gender, and tenure have no relationship with change self-efficacy and affective commitment to change.

\section{CONCLUSIONS}

This study investigates the effect of LMX and its dimension (professional respect, affect, contribution, and loyalty) on affective commitment to change, and the role of change self-efficacy as a mediator in the relationship between LMX and affective commitment to change. The results showed that the dimensions of LMX, affect and contribution have a significant positive relationship with affective commitment to change. Furthermore, the results found a mediating role of change self-efficacy in the relationship between the dimensions of LMX affect and contribution, with affective commitment to change. Research on LMX as a multidimensional linked to outcomes is still limited. Based on these findings, together with the limitations of the study, future research must examine the relationship of the dimensions of LMX with various other outcomes in different industries and across culture settings, to gain a more comprehensive understanding about the relationship of the dimension of LMX as multidimensional with various outcomes and other possible mediator or moderator variables.

\section{REFERENCES}

[1] I. Palmer, R. Dunford, and G. Akin, Managing organizational change: A multiple perspectives approach, 2nd ed. New York, NY: McGraw-Hill, 2009.

[2] P. Myers, S. Hulks, and L. Wiggins, Organizational change: Perspectives on theory and practice. Oxford, UK: Oxford University Press, 2012.

[3] W. L. H. Mangundjaya, Psikologi dalam perubahan organisasi. Jakarta: Swasthi Adi Cita, 2016.

[4] L. Herscovitch and J. P. Meyer, "Commitment to organizational change: Extension of a threecomponent model," J. Appl. Psychol., vol. 87, no. 3, pp. 474-487, 2002.

[5] M. N. Khan and M. F. Malik, “"My leader's group is my group'. Leader-member exchange and employees' behaviours," Eur. Bus. Rev., vol. 29 , no. 5, pp. 551-571, 2017

[6] C. R. Gerstner and D. V Day, "Meta-Analytic review of leader-member exchange theory: Correlates and construct issues.," J. Appl. Psychol., vol. 82, no. 6, p. 827, 1997.

[7] R. C. Liden and J. M. Maslyn, "Multidimensionality of leader-member exchange: An empirical assessment through scale development," J. Manage., vol. 24, no. 1, pp. 4372,1998

[8] S. Rashid, G. Dastgeer, and T. Kayaniv, "A social exchange perspective through the lens of an individual: Relationship between LMX, voice and organizational commitment in academia," Bus. Econ. Rev., vol. 10, no. 3, pp. 1-28, 2018.

[9] T. Rockstuhl, J. H. Dulebohn, S. Ang, and L. M. Shore, "Leader-member exchange (LMX) and culture: A meta-analysis of correlates of LMX across 23 countries," J. Appl. Psychol., vol. 97, no. 6, pp. 1097-1130, 2012.

[10] R. P. Setton, N. Bennet, and R. C. Liden, "Social exchange in organizations: Perceived organizational support, leader-member exchange, and employee reciprocity," J. Appl. Psychol., vol. 81, no. 3, pp. 219-227, 1996.

[11] F. Luthans, Perilaku Organisasi, (Alih Bahasa VA Yuwono, dkk), Ed. Bhs. Indones. Yogyakarta: ANDI, 2006. 
[12] D. M. Herold, D. B. Fedor, and S. D. Caldwell, "Beyond change management: A multilevel investigation of contextual and personal influences on employees' commitment to change," J. Appl. Psychol., vol. 9, no. 4, pp. 942-951, 2007.

[13] D. T. Holt, A. A. Armenakis, H. Field, and S. G. Harris, "Toward a comprehensive definition of readiness for change: A review of research and instrumentation," Res Organ Change Dev, vol. 16, pp. 289-336, 2007.

[14] R. C. Liden, S. J. Wayne, and D. Stilwell, "A longitudinal study on the early development of leader-member exchanges," J. Appl. Psychol., vol. 78, no. 4, pp. 662-674, 1993.

[15] D. M. Herold, D. B. Fedor, S. Caldwell, and Y. Liu, "The effects of transformational and change leadership on employees' commitment to a change: A multilevel study," J. Appl. Psychol., vol. 93, no. 2, p. 346-357, 2008.

[16] C. R. Wanberg and J. T. Banas, "Predictors and outcomes of openness to changes in a reorganizing workplace," J. Appl. Psychol., vol. 85, no. 1, pp. 132-142, 2000.

[17] Z. Liao, W. Liu, X. Li, and Z. Song, "Give and take: An episodic perspective on leader-member exchange," J. Appl. Psychol., vol. 104, no. 1, pp. 34-51, 2018.

[18] J. M. Maslyn and M. Uhl-Bien, "Leader-member exchange and its dimensions: Effects of self-effort and other's effort on relationship quality," J. Appl. Psychol., vol. 86, vol. 4, pp. 697-708, 2001.

[19] G. B. Graen and M. Uhl-Bien, "Relationship-based approach to leadership: Development of leadermember exchange (LMX) theory of leadership over 25 years: Applying a multi-level multidomain perspective," Leadersh. Q., vol. 6, no. 2, pp. 219-247, 1995.

[20] A. Yousaf, K. Sanders, N. Torka, and J. Ardts, "Having two bosses: Considering the relationships between LMX, satisfaction with HR practices, and organizational commitment," Int. J. Hum. Resour. Manag., vol. 22, no. 15, pp. 3109-3126, 2011.

[21] B. Ling, Y. Guo, and D. Chen, "Change leadership and employees' commitment to change: A multilevel motivation approach," J. Pers. Psychol., vol. 17, no. 2, pp. 83-93, 2018.
[22] D. Giovanita and W. L. H. Mangundjaya, "Transformational Leadership vs Change SelfEfficacy and Its Impact on Affective Commitment to Change," J. Mgt. Mkt. Rev., vol. 2, no. 4, pp. 1318, 2017.

[23] S. J. Ashford, "Individual strategies for coping with stress during organizational transitions," $J$. Appl. Behav. Sci, vol. 24, no. 1, pp. 19-36, 1988. 